the acceptor channel, post-acquisition data manipulation can be streamlined. Quantitative methods of spectral FRET detection and analysis have been developed and compared to data acquired using FLIM instrumentation (Thaler et al. 2005). Also, spectral imaging and unmixing technology provides the ability to successfully use FRET pairs with greater overlap, such as GFP-YFP (Zimmermann et al., 2002). Pairs with greater overlap can yield increased FRET efficiency.

Mattheyses, Hoppe, and Axelrod (2004). 'Polarized Fluorescence Resonance Energy Transfer Microscopy' Biophysical Journal 87:2787-2797.

Rizzo and Piston (2005). 'High-Contrast Imaging of Fluorescent Protein FRET by Fluorescence Polarization Microscopy?. Biophysical Journal: Biophysical Letters L14-L16.

Thaler, Koushik, Blank and Vogel (2005). 'Quantitative Multiphoton Spectral Imaging and its use for Measuring Resonance Energy Transfer.' Biophysical Journal 89:2736-2749.

Zimmermann, Rietdorf, Girod, Georget, and Pepperkok (2002). 'Spectral imaging and linear un-mixing enables improved FRET efficiency with a novel GFP2-YFP FRET pair.' FEBS Letters 531: 245-249.

\section{Microscopy for Children}

\section{Caroline Schooley \\ MSA Project MICRO \\ schooley@mcn.org}

Precollege science education in the United States is not what it could, and should, be. Major changes are being made in the way science is taught, but delivering those changes to thousands of schools is an enormous task. Scientific societies are a major resource; they can organize and train member-volunteers to help teachers bring "real" science to the classroom. The Microscopy Society of America has become part of the effort with Project MICRO (Microscopy In Curriculum - Research Outreach). MICRO is putting MSA members, teaching materials, and microscopes in middle school classrooms nationwide. The idea began in 1993, but it has taken a lot of time and effort to implement.

MSA's early decision to collaborate with experienced science educators at the Lawrence Hall of Science of the University of California at Berkeley was a wise one; their educational materials have a well-earned national reputation for excellence. The first phase of MICRO was completed in July 1998 with the publication of a teacher's manual, Microscopic Explorations in the LHS GEMS (Great Explorations in Math and Science [www.lhs.berkeley.edu/GEMS/GEMS. html ] series, which is a leading resource for the advancement of activity-based science and mathematics nationally and worldwide. GEMS activities are originated at the Lawrence Hall of Science, the public science and curriculum development center of the University of California at Berkeley, and thoroughly tested by teachers nationwide before publication. GEMS units use accessible everyday materials and are designed for successful presentation by teachers who may or may not have special background in math or science. Featuring the "guided discovery" inquiry-based approach, GEMS units can stand alone as stimulating ways to involve all students in science and math, or can be combined to construct creative and effective year-long curricula. Among the many facets of the LHS GEMS program are:

- An acclaimed series of more than 70 teacher' guides and handbooks, including the MSA/GEMS guide, Microscopic Explorations
- Specialized teacher's workshops offered locally and nationally

- A growing national and international network of GEMS Sites and Centers

- Thousands of trained GEMS Leaders and GEMS Associates who support the MSA/MICRO effort to get microscopist-volunteers into classrooms nationwide.

A description of the collaboration between MSA and the LHS that produced Microscopic Explorations appears in vol. 2, \#1 (Spring '03) of Cell Biology Education, a new online journal [http://www. cellbioed.org/articles/vol2no1/toc.cfm].

Where do we go from here? MICRO isn't just a manual. Publishing a GEMS guide brings the excitement of the microworld into thousands of classrooms. In the years since then, Microscopic Explorations has become an educational best- seller, with three printings and over 11,000 copies sold. During the same years, the general success of the GEMS program has led to the development of a national network of training centers that introduce teachers to the methods and concepts used in the series. This is important to you as a microscopist, because YOU can get help from the centers too. You can help a center present a Microscopic Explorations workshop for teachers, or the center can introduce you to a teacher who wants help. You'll find a list of centers on the GEMS website. And when it's possible to get a microscopist-volunteer into the classroom to help present the material, much can be accomplished. The availability of volunteers encourages hesitant teachers to use microscopy. Microscopist-volunteers take the enthusiasm generated by the manual content down many lines of inquiry, to be determined by the needs of the classes and the skills of the volunteers.

MICRO has gained an unexpected major benefit from its association with the LHS. The main problem faced by other scientific societies that have begun outreach programs has been national support of training, both for teachers and volunteers. The LHS/GEMS program is so successful that they've outgrown their ability to provide enough in-house trainers to meet the demand. So in the period since MICRO's inception, a highly trained category of teacher-trainer, "GEMS Associates" has been developed. There now are hundreds of them, all over the country. Geographic coverage is still spotty, but the numbers are growing rapidly. GEMS Associates can help MSA's local societies organize programs, and in areas that aren't served by participating local societies, they can invite individual microscopistvolunteers to attend GEMS workshops and then help them find a teacher to work with.

\section{Endnotes}

Great Explorations in Math and Science (GEMS) [http://www.lhs. berkeley.edu/GEMS/GEMS.html ]

Sites and Centers launched recently, with date of launch:

Willimantic, Connecticut Site 10/03

Atlanta, Georgia Site 3/04

Carson City, Nevada Site 6/05

Sacramento, California Site 8/05

Mt. Pleasant, Michigan GEMS Center 9/05

Keene, New Hampshire GEMS Site 10/05

Gainesville, Florida GEMS Site 10/05

Pierre, South Dakota GEMS Site (Summer, 2006)

Contact information for all of these new GEMS sites is posted at http://lhsgems.org/sitescenters.html

If you're an overseas reader of Microscopy Today, please note that there are also GEMS centers in Europe, the Middle East, and Asia! 